\title{
ACOUSTIC EMISSION UNDER TEMPERATURE TESTS OF MATERIALS
}

\author{
V. Babak, S. Filonenko, V. Kalita
}

National Aviation University, Kiev, Ukraine.E-mail:fils@ukrpost.net

Received 0411 2004, accepted 05122005

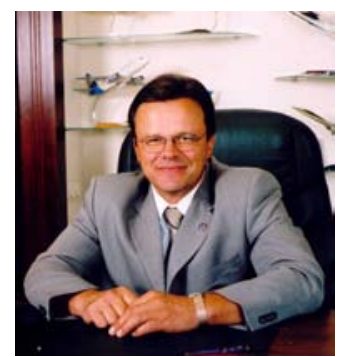

Vitalii BABAK, Prof Dr Habil

Date and place of birth: 1954, Lubny, Ukraine.

Education: Kiev Polytechnic Institute.

Affiliation and functions: Rector of the National Aviation University since 1998, 1995 - PhD from Kiev Polytechnic Institute.

Research interests: diagnostics of technological processes, laser and computer modeling and manufacturing, automatic diagnostics systems.

Publications: over 300 books and articles.

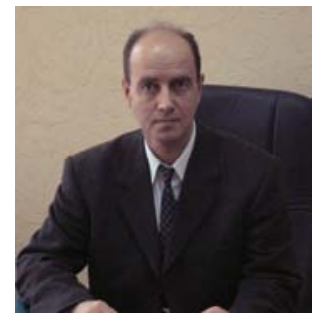

Sergay FILONENKO, Prof Dr Habil

Date and place of birth: 1954, Echmiadzin, Armenia.

Education: Kiev Polytechnic Institute.

Affiliation and functions: deputy director of Institute of Information-Diagnostic Systems at National Aviation University since 2000, 2003 - PhD from National Aviation University.

Research interests: diagnostics of technological processes, automatic diagnostic systems

Publications: over 130 books and articles.

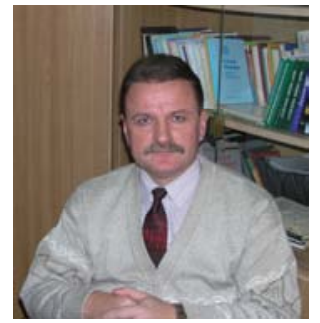

\section{Viktor KALITA,}

Date and place of birth: 1962, Chernigov, Ukraine

Education: Rostov on Don State University

Affiliation and functions: assistant professor of physics, National Aviation University since 2000, 1991 Cand.of Sci. (Eng.) from Rostov on Don State University

Research interests: solid-state physics, technical diagnostic

Publications: over 46 articles.

\begin{abstract}
The theoretical research of the influence of temperature on the parameters of the alteration of acoustic emission signals from plastic deformation is considered. It is shown that increasing temperatures cause an increase in the amplitude of acoustic emission signals in an area of low temperatures and a decrease in an area of high temperatures. At the same time, there is an intermediate area of temperatures in which the amplitude of acoustic emission signals remains constant when temperature is increased. As shown in the article, this fact is connected with the alteration of the process of plastic deformation.
\end{abstract}

Keywords: model, acoustic emission, strength, dislocation, plastic deformation, loading, signal of acoustic emission, distribution of strength, fracture, temperature, structural heterogeneity.

\section{Introduction}

In industry there is a significant amount of equipment that operates work not only in conditions of mechanical, but also temperature deformations. This includes the equipment used by petrochemical, gas and power manufacturers and equipment for aviation and space purposes. Temperature loading, depending on operation conditions, covers high and low areas of temperatures. Certainly, the temperature is the factor that influ- ences physico-mechanical characteristics of materials that should be reflected in acoustic emission signals (AE) that arise during plastic deformation and growth of cracks.

AE signal models were developed at the formation of a fragile crack and the process of plastic deformation under the conditions of mechanical loading of the material $[4,6]$. It has been shown, that at crack formation the resulting elastic displacement (AE signal) were defined by the physico-mechanical characteristics of the material, 
In case of plastic deformation, the resulting displacement has been defined by a number of movable dislocations and time (velocity) of the course of plastic deformation. Modeling AE signals according to the developed models and on the basis of existing views on the development of plastic deformation processes, crack formation, and growth, has shown their good coordination with results of experimental research [7, 5]. However, the developed models of AE signals take into account only the influence of mechanical loading and the acceleration or slowing down of processes that take place in the material structure at loading. At the same time, temperature will influence the character of the development of the given processes and should lead to the alteration of the parameters of the AE of signals, both at formation of a crack, and during plastic deformation. It is therefore necessary to analyze the influence of temperature on the parameters of AE signals according to the developed models.

For the AE signal at a fragile crack formation, the influence of temperature can probably be shown as the change in the distribution of elementary volumes after strength and alteration of its parameters. To carry out such an analysis, it is therefore necessary to know the dependence of the change of strength distribution on temperature in the area of material where the formation of a crack is observed. The study of such distribution, using the approach developed to create the AE signal model of the fragile crack $[4,6]$, allows the analytical description of the signal formed and alteration of its parameters to be determined easily enough. Absolutely another situation takes place at formation of the AE signal from plastic deformation when its development occurs on the base of the dislocation mechanism. Thus, according to the results received in the work [4], the parameters of the AE signal from plastic deformation are defined, both by number of movable dislocations, and by conditions of their movement, i.e. factors which depend directly on temperature.

Under such circumstances, the description of the AE signal formed becomes complicated considerably due to the existence of several parameters that depend on temperature and that influence the AE signal. It is connected with the complexity of processes of plastic deformation depending on the area of researched temperatures - low, average, or high.

In this work, the analysis of the influence of temperature on the parameters of the AE signal that is formed at plastic deformation in material will be performed according to the model proposed in [4].

\section{Results of research}

Plastic deformation, as is known, is caused by the movement of dislocations that move, make multiple copies, and stop during material deformation $[3,2,1]$. The process of their movement is accompanied by AE signals that appear because they overcome the barriers (potential barriers) by movable dislocations, which was considered in the model of AE signal from plastic deformation [4,
5]. Thus the analytical expression of the AE signal has been determined as

$$
U_{D}(t)=u_{o} \alpha t \exp (-B \alpha t)
$$

where $u_{o}=a_{o} M \frac{v_{D}}{\ell_{0}} \delta_{D} ; a_{o}-$ peak value of a single displacement pulse is generated by a movable dislocation (Fig. 1$) ; \delta_{D}$ - average duration of an indignation pulse; $\ell_{o}-$ a distance between two generation acts; $v_{D}-$ a velocity of dislocation movement, which is considered as a constant; M, B - the constants dependent on physicomechanical characteristics of material; $\alpha$ - velocity of material loading.

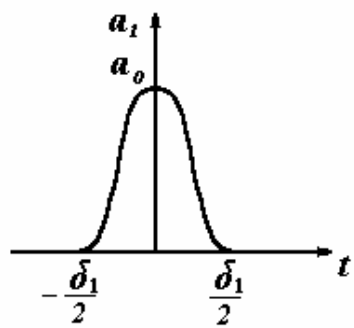

Fig. An indignation pulse at separation of a single dislocation or at overcoming the dislocation barrier

When developing an AE signal model from plastic deformation, it was considered that the deformation of material occurs at a constant temperature that does not influence its physico-mechanical characteristics. At that time, the parameters that are included into the description of the resulting AE signal (1) and that are connected to the movement of dislocations depend on temperature. It concerns, first of all, the average speed of the movement of dislocation, and the number of movable dislocations $\left[8,{ }^{*}\right]$.

Besides that, the parameters of the indignation pulse (its amplitude and duration) that is generated when the dislocation barrier is overcome certainly depends on temperature, because as the temperature influences the number of potential barriers and their modification. It is therefore possible to describe the influence of temperature on the resulting $\mathrm{AE}$ signal at the development of plastic deformation (1), as

$U_{D}(t, T)=a_{o}(T) \frac{v_{D}(T)}{\ell_{o}} \delta_{D}(T) \alpha_{D} t M(T) \exp \left(-B(T) \alpha_{D} t\right)$,

where it is expected that $a_{O}(T)$ - a peak value of a single displacement pulse (Fig.1) that is formed when a dislocation barrier is overcome; $\delta_{D}(T)$-duration of the indignation pulse; $v_{D}(T)$ - average velocity of dislocation movement, which depends on temperature.

Parameters $M(T)$ and $B(T)$ also depend on temperature, and they define the number of movable dislocations under a given deformation. According to expression (2), it is expected that at first plastic deformation in a local area of the material develop at the velocity of the external

\footnotetext{
* Сопротивление материалов к деформированию и разрушению: Справочное пособие /В. Т. Трощенко, А. Я. Красовский, В. В. Покровский др. - К. Наукова думка, 1994. - Ч. 2. - 702 с.
} 
load, and its time dependence is defined only by conditions of external loading. Second, we consider that the distance between barriers at temperature alteration remains unchangeable i.e. $\ell_{0}=$ const. This is possible if we assume that at a change in temperature in material new defects, which are barriers for the movement of dislocations, are not formed. On the other hand, it is possible to neglect the alteration of $\ell_{0}(T)$ when other parameters, which are in expression (1) and depend on temperature, change quicker than $\ell_{0}(T)$.

It is necessary to note again that when developing the model of the AE signal from plastic deformation, which is described by expression (1), it was considered that the moment of time $t=0$ corresponds to the beginning of plastic deformation. This pertains to expression (2). Note also that when analyzing the influence of temperature on the AE signal, one local area where plastic deformation is developed is considered. Herewith, it is absolutely obvious that with the increase in temperature the development of plastic deformation occurs under a lower load. This will lead to a shift in the time of the generation of the AE signal, i.e. signals begin to be formed earlier at high temperatures.

Average velocity of dislocation, as described in [11, $12]$, increases when the temperature grows and is defined by the expression

$v_{D}=A \omega_{0} \exp \left[-\frac{U_{0}-\vartheta\left(\tau-\tau_{G}\right)}{k T}\right]$,

where $A-$ an area that is engulfed by the length of dislocation between two consequent activations; $\omega_{0}-$ Einstein frequency of atom fluctuations; $\vartheta$-activation volume; $U_{0}-\vartheta\left(\tau-\tau_{G}\right)$ - an energy of activation of the dislocation displacement that depends on efficient strain; $\tau$-attached strain; $\tau_{G}$ - an internal strain that is caused by elastic interaction between dislocation and which resists the dislocation slide; $\mathrm{k}$ - Boltsman constant; $\mathrm{T}$ - an absolute temperature.

Having substituted expression (3) in formula (2), we determine that temperature of the AE signal depends on plastic deformation and can be described by the following expression

$$
\begin{aligned}
& U_{D}(t, T)=a_{o}(T) \frac{A \omega_{0}}{\ell_{o}} \exp \left[-\frac{U_{0}-\vartheta\left(\tau-\tau_{G}\right)}{k T}\right] \mathrm{x} . \\
& \delta_{D}(T) \alpha_{D} t M(T) \exp \left(-B(T) \alpha_{D} t\right)
\end{aligned}
$$

From expression (4), it is seen that the way that the AE signal depends on temperature change is rather complicated. The influence of temperature on AE signals under plastic deformation is conditioned by a number of definite temperature parameters. Certainly, the modeling of such influence when it is uncertain how temperature influences all the noted parameters is a difficult problem. However, it is possible to select and to consider two principle factors, i.e. the influence of temperature on the velocities of the dislocation movement and the influence of the temperature on quantitative parameters, which describe the number of movable dislocations from the level of deformation. When considering the influences of these factors, let us assume that the type of barriers ant the level of these barriers do not depend on the temperature. Besides, let us also assume that overcoming barriers by dislocation occurs in an elastic way. With such an approach, it is possible to consider that amplitude of indignation pulses $\mathrm{s}$ does not depend on temperature, i.e. $a_{o}(T)=$ const, but in the same way the average duration of the indignation pulse remains constant, i.e. $a_{o}(T)=$ const.

To clarify the influence of temperature on AE signals, taking into account our assumption, it is reasonable to consider the ratio of the quantities of two signals that are determined at different temperatures, for instance, at temperature $T_{1}$ and $T_{2}$, when $T_{1}<T_{2}$. Then, according to expression (4) such ratios can be written as follows

$$
\begin{aligned}
& \frac{U_{D}\left(t, T_{2}\right)}{U_{D}\left(t, T_{1}\right)}=\frac{a_{0}\left(T_{2}\right)}{a_{0}\left(T_{1}\right)} \frac{\exp \left[-\frac{U_{0}-\vartheta\left(\tau_{2}-\tau_{G 2}\right)}{k T_{2}}\right]}{\exp \left[-\frac{U_{0}-\vartheta\left(\tau_{1}-\tau_{G 1}\right)}{k T_{1}}\right]} \mathrm{x}, \\
& \frac{\delta_{D}\left(T_{2}\right)}{\delta_{D}\left(T_{1}\right)} \frac{M\left(T_{1}\right)}{M\left(T_{2}\right)} \frac{\exp \left(-B\left(T_{2}\right) \alpha_{D} t\right)}{\exp \left(-B\left(T_{1}\right) \alpha_{D} t\right)}
\end{aligned}
$$

where $\tau_{G 1}$ and $\tau_{G 2}$ - internal strains at temperatures $T_{1}$ and $T_{2}$ that are caused by elastic interplay between dislocations that resist dislocation sliding; $\tau_{1}$ and $\tau_{2}$ - external strains under which plastic deformation occurs at temperatures $T_{1}$ and $T_{2}$.

Note that in expression (5) AE signals are considered by their own time.

As follows from expression (5), components of the first ratio (the numerator and denominator) are connected with the alteration of the velocities of dislocations due to temperature, but other components are connected with the alteration of the density of movable dislocations due to temperature.

We shall first consider the influence of a change in the velocity of movable dislocations, which are changed at the temperature alteration, upon the AE signal. We can consider that parameters $M(T)$ and $B(T)$ will remain constant while temperature increases. This means that the number of movable dislocations does not depend on temperature and remains constant at a predetermined magnitude of deformation and change in temperature. This assumption is possible when the material within which plastic deformation occurs remains unchanged at a change in temperature. In other words, if an AE signal model from plastic deformation is developed, we have considered a certain local area with a given nonhomogenous volume in which deformation occurs while at the temperature alteration the volume of the given local area remains unchanged [4].

Thereby, for the case when $\mathrm{M}(T)=V(T)=$ const, when temperatures are altered, only the velocity of the dislocation movement will be changed. Then the ratio for amplitudes of AE signals from plastic deformation under different meaning of the temperature $T_{1}$ and $T_{2}\left(T_{1}<T_{2}\right)$, according to expression (5), will be written in the form of 


$$
\frac{U_{D}\left(t, T_{2}\right)}{U_{D}\left(t, T_{1}\right)}=\exp \left[-\frac{U_{0}-\vartheta\left(\tau_{2}-\tau_{G 2}\right)}{k T_{2}}\right] / \exp \left[-\frac{U_{0}-\vartheta\left(\tau_{1}-\tau_{G 1}\right)}{k T_{1}}\right]
$$

Analyzing expression (6), it is necessary to separate the area of low and high temperatures that is connected with different influence of the resistance to sliding of dislocations at these temperatures.

As described in $[8,10]$, the strain that is necessary for generation of dislocations increases at low temperature. At low temperature, it is possible to consider that the amount of formed (and, in general, movable) dislocations is small. Thereby, in the area of "low temperature", it is possible to neglect the temperature effect. Besides, under low temperature, plastic deformation (more exactly micro plastic deformation) occurs under rather high values of strain $\tau$. So it is possible to neglect its alteration, i.e. consider that $\tau_{1} \approx \tau_{2}$. Then it is possible to rewrite expression (6) in the manner of

$\frac{U_{D}\left(t, T_{2}\right)}{U_{D}\left(t, T_{1}\right)}=\exp \left[\frac{U_{0}-\vartheta\left(\tau-\tau_{G}\right)}{k T_{1}}\left(1-\frac{T_{1}}{T_{2}}\right)\right]$,

in which it is in the same way taken into account that $\tau_{G}\left(T_{1}\right)=\tau_{G}\left(T_{2}\right)$.

If we determine the logarithm from expression (7), we shall get

$$
\ln \left(\frac{U_{D}\left(t, T_{2}\right)}{U_{D}\left(t, T_{1}\right)}\right)=\frac{U_{0}-\vartheta\left(\tau-\tau_{G}\right)}{k T_{1}}\left(1-\frac{T_{1}}{T_{2}}\right) .
$$

It is seen from expression (8) that in the area of low temperature logarithm ratios of the amplitudes of $\mathrm{AE}$ signals under unchanged local volume of the material that has been involved in plastic deformation is inversely proportional to temperature. In other words, at increasing temperature an increase in the amplitudes of the AE signal will occur.

Note that correlations (7) and (8) are executed until the amount of dislocations formed is small and does not influence the alteration in the value of the elastic interaction between dislocations. The principle difference from the previous case is therefore the significant increase in temperature, when the conditions mentioned above are not provided. At high temperature, the strain, under which the generation of dislocations takes place, decreases, causing an increase in the amount of dislocations formed. Because of this, the strain of the interaction between them $\left(\tau_{G}\right)$ increases. So, at temperature $T_{2}>T_{1}$, the inequality $\tau_{G}\left(T_{2}\right)>\tau_{G}\left(T_{1}\right)$ is observed. The growth of $\tau_{G}$, as is shown in $[8,10]$, is a factor that slows the movement of dislocations - see expression (3). This means that the inverse proportion of the logarithm ratio of amplitudes due to temperature described above, in accordance with expression (8), will not be executed, but in accordance with expression (6) the ratio of amplitudes of AE signal, in consequence of the action of this factor, must decrease.

At the same time, an increase in the amount of dislocation is accompanied by their blockage and, as a result of this, by on decrease in the number of these disloca- tions. The reduction in the amount of movable dislocations at increase in temperature corresponds to the reduction of parameter $M(T)$ in association with the alteration in the amount of movable dislocations from deformation. However, an increase in the level of plastic deformation is observed at an increase in temperature $\left[{ }^{*},{ }^{* *}\right]$. This happens because the increase in distances that are passed by moving dislocations corresponds to a decrease in parameter $B(T)$ in the expression mentioned above. So, the ratio of the amplitudes of $\mathrm{AE}$ signals at an increase in temperature will be different than expression (5) and can be presented as follows

$\frac{U_{D}\left(t, T_{2}\right)}{U_{D}\left(t, T_{1}\right)}=\frac{\exp \left[-\frac{U_{0}-\vartheta\left(\tau_{2}-\tau_{G}\left(T_{2}\right)\right)}{k T_{2}}\right]}{\exp \left[-\frac{U_{0}-\vartheta\left(\tau_{1}-\tau_{G}\left(T_{1}\right)\right)}{k T_{1}}\right]} \mathrm{x}$.

$M\left(T_{2}\right) \exp \left(-\alpha B\left(T_{2}\right) t\right)$

$M\left(T_{1}\right) \exp \left(-\alpha B\left(T_{1}\right) t\right)$

Thereby, if the area of high temperatures is considered, then in the first part of expression (9) except influence upon velocity of the dislocations movement of the $\tau_{G}(T)$ value the influence of the value of $k T$ can be seen. Their action is reciprocally opposite. It is necessary to take into account that at alteration of temperature values the magnitude of the stress $\tau_{G}(T)$ has got accelerated non-linear growth. So, in the field of high temperature, this factor will have primary importance [8]. Besides, the beginning of plastic deformation under high temperature will occur under smaller quantities of strain i.e. $\tau_{2}<\tau_{1}$. So, when temperature increases, the first ratio in expression (9) will certainly decrease.

On the other hand, when the number of movable dislocations drops, the second ratio in expression (9) will also decrease. Thereby, in an area of high temperature, it is possible to expect that temperature increases, the ratio of amplitudes of the AE signals will decrease. This corresponds to the results of the experimental studies of $\mathrm{AE}$ signals during tests of samples of materials at high temperatures, in which the decrease of the amplitude of AE signals with the increase of temperature is observed, as is shown, for instance, in work [9] for steel $20 \mathrm{X}$ at temperatures above $593 \mathrm{~K}$.

Thereby, in the process of plastic deformation of material under temperature growth, when the initial temperature is low enough, an increase in the amplitude of the AE signals takes place (7). In an area of high temperature, on the contrary, an increase in temperature causes a decrease in the amplitude of the AE signals (9). Between these temperature areas, a transitional temperature area, where the amplitude of $\mathrm{AE}$ signals is practically not changed due to the temperature, will exist. This is shown in experimental studies [9]. It is probably connected to the fact that in expression (9) the products of the numerator to products of the denominator do not de-

\footnotetext{
* Сопротивление материалов к деформированию и разрушению: Справочное пособие /В. Т. Трощенко, А. Я. Красовский, В. В Покровский др. - К. Наукова думка, 1994. - Ч. 2. - 702 с.

Ibid. 1993. - Ч. 1. $-288 \mathrm{c}$.
} 
pend on temperature. Under such temperature, a reduction in strain takes place. This drop corresponds to the beginning of plastic deformation $(\tau)$, with in a gradual growth in the number of dislocations (a reduction the voltage of dislocation generations occurs). At that time, under given condition, the value $\tau_{G}(T)$ must increase. However, in accordance with the increase in the overall amount of dislocations, the $\tau_{G}(T)$ increase probably occurs not so quickly, as in the area of high temperature that, in its turn, promotes the increase in the number of movable dislocations.

Therefore, the low temperature dependence of the products of the numerator and the denominator in expression (9) is connected with the reduction of $\tau$ and the increase of $\tau_{G}(T)$; it will be compensated for by the increase in the number of movable dislocations. However, through uncertainty of temperature dependence on the strains $\tau(T), \tau_{G}(T)$, and parameters $M(T), B(T)$, the mathematical description of such compensation is a difficult task and is impossible to put into the framework of an executed phenomenological approach. Note, that in the work quoted above [9] it is shown experimentally that for $20 \mathrm{X}$ steel in an interval of temperature $300 \mathrm{~K}$ $573 \mathrm{~K}$ the amplitude of AE signals practically does not change, but if temperature is higher than $573 \mathrm{~K}$, a stable decrease in the amplitude of the AE signals occurs. It is interesting that under all studied temperatures, the authors noted that modifications of material structure were not revealed by means of their structural analysis. This indicates that the temperature peculiarities of AE signal generation are determined by conditions at the origin of the dislocations and their movement, which completely matches with the results of the analysis performed.

\section{Conclusions}

The results of the study carried out have shown that the influence of temperature on AE signals is defined the plastic deformation process and explains AE signal experimental test data that have been recorded and processed. The data were received during a temperature test of 20X steel samples. In this work, it is shown that in an area of low temperatures an increase in temperature is followed by an increase in the amplitudes of AE signals. Under high temperature, on the contrary, an increase in temperature is followed by a decrease in the amplitudes of AE signals. A transitional area of temperature must exist in which temperature growth is not accompanied by an alteration in the amplitudes of AE signals.

\section{References}

1. Chandra B.P., Gour A.S., Chandra V.K. et al. Dislocation unpinning model of acoustic emission from alkali halide crystal // Journal of Phisics. - Ind. Acad. of Scienses, 2004. - Vol 62, No 6. - P.12811292.

2. Cotrell A.H. Theory of crystal dislocation. - New York: Gordon and Breach, 1964.

3. Gilman I.I. Progress in microdynamical theory of plasticity // Proceedings of the 5-th National Congress on Applied Mechanics. - New York: ASME, 1966. - P. 385- 403.

4. Бабак В.П., Филоненко С.Ф., Калита В.М. Модели формирования сигналов акустической эмиссии при деформировании и разрушении материалов // Технологические системы. - 2002. - № 1 (12). - C.26-34.

5. Бабак В.П., Филоненко С.Ф., Калита В.М. Моделирование сигналов акустической эмиссии при протекании в материале пластической деформации // Технологические системы. - 2002. -№ 3 (14). - C.77-81.

6. Бабак В.П., Филоненко С.Ф., Калита В.М. Модель сигнала акустической эмиссии при образовании в материале трещины с учетом релаксационных процессов // Технологические системы. - 2002. - № 5(16). - С. 20-23.

7. Бабак В.П., Філоненко С.Ф., Калита В.М. Моделювання сигналів акустичної емісії при виникненні в матеріалі тріщин // Вісник НАУ. 2002. - № 1. - C. 5-10.

8. Бернштейн М.Л., Займовский В.А. Структура и механические свойства металлов. - $\mathrm{M}$ : Издательство Металлургия, 1970.-472 с.

9. Вайнберг В.Е. Температурная зависимость акустической эмиссии // Дефектоскопия. - № 5, 1976. - С. 124-126.

10. Киттель Ч. Введение в физику твердого тела. М: Наука, 1978. -792 с.

11. Маламедов И.М. Физические основы надежности. - Л.:Энергия, 1970. - 152 с.

12. Регель В.Р., Слуцкер А.И., Томашевский Э.Е. Кинетическая природа прочности твердых тел. М.: Наука, 1974. - 560 с. 